\title{
Urgency of government physiotherapy college in bangladesh
}

Volume 6 Issue 6 - 2017

\section{Opinion}

Physiotherapy is a clinical subject, specialized branch of medical science, evidence based, wide-spread application and effective treatment for all ages. According to World Health Organization those who completed at least Bachelor degree of Physiotherapy is considered as Physiotherapist who is an independent medical professional and able to diagnose and treat patient as well. In developed world like USA undergraduate, post graduate and doctoral level physiotherapy course is running now and they announced within 2020 almost all courses of physiotherapy will be transformed into Doctor of Physiotherapy (DPT). Even our neighboring country Pakistan they also started Doctor of Physiotherapy. There are number of Government run physiotherapy college/institute in India but regret to say there is no single Government run separate physiotherapy college in Bangladesh yet though non-communicable diseases like stroke, diabetes, arthritis are increasing day by day due to altering of life style. In Bangladesh both undergraduate and post graduate physiotherapy courses is running now under Faculty of Medicine and according to Bangladesh Physiotherapy Association (www. bd-bpa.org) total graduate physiotherapists is now around 3000 and every year fresh physiotherapists are adding but there is scope of Government job for them. Most of them are doing private practice and $\mathrm{NGO}$ job. It is mentionable that Government has given land, fixed money for Bangladesh College of Physiotherapy due to pressure of student's movement couple of years back but still no implementation is seen. As a result lot of patients suffering from arthritis, stroke, back pain, neck pain, frozen shoulder, disability, sports injury are depriving from quality physiotherapy services from public hospital. Moreover number of medical and dental colleges are increasing rapidly even nursing institute/college also but students and professionals are still fighting to set up Bangladesh College of Physiotherapy. Once upon a time there was physiotherapy department in Govt. medical colleges but now it is changed into Physical Medicine and Rehabilitation

\section{Md Monoarul Haque}

Publication Secretary, Bangladesh Physiotherapy Association, Bangladesh

Correspondence: Md Monoarul Haque, Publication Secretary, Bangladesh Physiotherapy Association, Bangladesh, Email monoarmunna@yahoo.com

Received: January 12, 2017 | Published: May 26, 2017

department without any logical reason; tendency to occupy post of physiotherapists by other medical professionals which ultimately results technology/electrotherapy dependent treatment instead of real physiotherapy and wrong/inaccurate message is reaching to the patients that physiotherapy means heat (locally known Sacca). So time has come to think about this very much urgent issue. Concern authority as well as policy maker can solve this problem for the betterment of patients. Rehabilitation is the key component of World Health Organization. WHO can contribute in rehabilitation sector of Bangladesh by collaborating policy maker as well as Bangladesh Physiotherapy Association (www.bd-bpa.org).

\section{Acknowlegments}

None.

\section{Conflicts of Interest}

None. 